\title{
Immune complex formation impairs the elimination of solutes from the brain: implications for immunotherapy in Alzheimer's disease
}

Roxana Octavia Carare ${ }^{1,3^{*}}$, Jessica Liesbeth Teeling ${ }^{2 \dagger}$, Cheryl A Hawkes ${ }^{1}$, Ursula Püntener ${ }^{2}$, Roy O Weller ${ }^{1}$, James AR Nicoll ${ }^{1}$ and Victor Hugh Perry ${ }^{2}$

\begin{abstract}
Background: Basement membranes in the walls of cerebral capillaries and arteries form a major lymphatic drainage pathway for fluid and solutes from the brain. Amyloid- $\beta(A \beta)$ draining from the brain is deposited in such perivascular pathways as cerebral amyloid angiopathy (CAA) in Alzheimer's disease (AD). CAA increases in severity when $A \beta$ is removed from the brain parenchyma by immunotherapy for AD. In this study we investigated the consequences of immune complexes in artery walls upon drainage of solutes similar to soluble $A \beta$. We tested the hypothesis that, following active immunization with ovalbumin, immune complexes form within the walls of cerebral arteries and impair the perivascular drainage of solutes from the brain. Mice were immunized against ovalbumin and then challenged by intracerebral microinjection of ovalbumin. Perivascular drainage of solutes was quantified following intracerebral microinjection of soluble fluorescent 3kDa dextran into the brain at different time intervals after intracerebral challenge with ovalbumin.
\end{abstract}

Results: Ovalbumin, IgG and complement C3 co-localized in basement membranes of artery walls 24 hrs after challenge with antigen; this was associated with significantly reduced drainage of dextran in immunized mice.

Conclusions: Perivascular drainage along artery walls returned to normal by 7 days. These results indicate that immune complexes form in association with basement membranes of cerebral arteries and interfere transiently with perivascular drainage of solutes from the brain. Immune complexes formed during immunotherapy for AD may similarly impair perivascular drainage of soluble $A \beta$ and increase severity of CAA.

Keywords: Alzheimer's disease, Cerebral vasculature, Perivascular drainage, Basement membranes, Immunotherapy

\section{Background}

Unlike most other organs in the body, the brain has no conventional lymphatic drainage. However, experimental studies using soluble tracers in mice have shown that solutes injected into the interstitial fluid of the brain parenchyma drain along basement membranes in the walls of capillaries and arteries towards regional lymph nodes in the neck [1,2]. Following injection into the mouse striatum, ovalbumin (OVA, $49 \mathrm{kDa}$ ), fluorescent dextran

\footnotetext{
* Correspondence: rcn@soton.ac.uk

${ }^{\dagger}$ Equal contributors

${ }^{1}$ Faculty of Medicine, University of Southampton, Southampton, UK ${ }^{3}$ Clinical Neurosciences, South Lab and Pathology Block, LD66 (Mailpoint 806), Southampton General Hospital, Tremona Road, Southampton, Hampshire SO16 6YD, United Kingdom

Full list of author information is available at the end of the article
}

3-10 kDa, and soluble amyloid- $\beta(\mathrm{A} \beta)$ diffuse through the extracellular spaces of the brain and then enter the basement membranes of cerebral capillaries and arteries that act as the lymphatic drainage pathways of the brain [2]. With age and in Alzheimer's disease (AD), insoluble fibrillary $\mathrm{A} \beta$ is deposited in the walls of cerebral capillaries and arteries as cerebral amyloid angiopathy (CAA) [3-5]. Initially, $A \beta$ is deposited in intramural vascular basement membranes that form the lymphatic drainage pathways of the brain but eventually $A \beta$ may occupy the whole thickness of the walls of arteries and capillaries [6-8]. Rupture of amyloid laden vessels is associated with CAA related intracerebral haemorrhage $[9,10]$.

Levels of soluble $A \beta$ are also raised in the brain in $A D$ and this correlates with cognitive decline, suggesting 
that the elimination of soluble $A \beta$ from the brain may be impaired with age and AD $[11,12]$. Trials of immunotherapy for AD in humans were introduced following successful studies in transgenic mice showing that insoluble $A \beta$ plaques were removed from the brain following immunization with A $\beta 42[13,14]$. However, despite the clearance of $A \beta$ plaques from patients with $A D$, active immunization seems to increase, rather than decrease, the amount of arterial CAA in both transgenic mice and humans [15-17]. It appears that $A \beta$ can be solubilised from plaques but it becomes entrapped in the perivascular drainage pathways manifesting as an increase in the severity of CAA [18]. The dynamics of the events resulting in increased CAA following immunotherapy are not clear but it could reflect either an increased flow of soluble $A \beta$ out of the brain in the perivascular drainage pathways, or it may reflect impaired drainage and elimination of soluble $A \beta$ due to the formation of $A \beta$-anti-A $\beta$ immune complexes. In addition, trials of both active and passive $A \beta$ antibody therapy in patients with $\mathrm{AD}$ have encountered side-effects comprising focal abnormalities in cerebral white matter on imaging, suggesting an increasing fluid in the subcortical white matter, again reflecting failure of fluid drainage from the brain [19]. The pathophysiology underlying the sideeffects of $A \beta$ immunotherapy are as yet unclear but may be due in part to the effects of immune complexes forming in perivascular drainage pathways.

In previously published studies, we showed first that when OVA is injected into the mouse brain, it drains rapidly out of the brain along basement membranes in the walls of cerebral capillaries and arteries [2]. Secondly we showed that active immunization with OVA followed by the intracerebral injection of the antigen OVA, resulted in the formation of immune complexes in the brain parenchyma associated with a robust inflammatory response and macrophage activation [20].

In the present study, we first tested the hypothesis that immune complexes form in the interstitial fluid drainage pathways the walls of cerebral arteries of OVA-immunized mice following challenge with the antigen. Second, we tested the hypothesis that the presence of OVA immune complexes in cerebral artery walls disrupts the perivascular lymphatic drainage of soluble tracers from the brain.

\section{Methods}

Animals

BALB/c mice were originally obtained from Charles River (Margate, United Kingdom) and bred and maintained in local facilities. Animal experiments obtained approval from the local Committee for Ethics at the University of Southampton and were performed under Home Office licencing. A total number of 75 mice of 6-10 weeks old were used in this study.

\section{Active immunization}

8 week old Balb/c mice were immunized against OVA by intraperitoneal (i.p.) injection of $50 \mu \mathrm{g}$ OVA (SigmaAldrich, Dorset, UK) in the presence of Alum (1:1 ratio, Alum inject, Fisher Thermo, Loughborough, UK). Mice received a booster injection of $100 \mu \mathrm{g}$ OVA in saline at 2,4 and 6 weeks and 3 days before the intracerebral injection of OVA.

\section{Generation of immune complexes}

Mice were anaesthetized by intraperitoneal injection of $0.1 \mathrm{ml} / 5 \mathrm{~g}$ body weight Avertin (2,2,2 tribromoethanol in tertiary amyl alcohol). The scalp was shaved and local anaesthetic (Lignocaine 5\% from Biorex Laboratories Ltd) was placed in the external auditory meati as mice were positioned in a stereotaxic frame (Kopf Instruments, Tujunga, CA, USA). $10 \mathrm{mg}$ of OVA was freshly diluted in $1 \mathrm{ml}$ of saline, and $1 \mu \mathrm{l}$ injected into the striatum (bregma $1 \mathrm{~mm}$ anterior, lateral $1.5 \mathrm{~mm}, 2.5 \mathrm{~mm}$ deep) of OVA-immunized or control non-immunized mice. Injections were performed over a period of $2 \mathrm{mi}-$ nutes through a glass micropipette with an injecting tip of $<50 \mu \mathrm{m}$ (Sigma-Aldrich, Dorset, UK). Tissue was collected at 5 minutes $(n=6), 3 \mathrm{~h}(\mathrm{n}=3), 24 \mathrm{~h}(\mathrm{n}=12)$, or 7 days $(n=12)$ after the injections. For analysis of immune complex formation, mice were perfused with heparinized saline and brains immediately frozen in Tissue Tek OCT (Sakura Finetek Europe B. V., Zoeterwoude, The Netherlands). Blood samples were taken to assess OVAspecific antibody titers by ELISA and described before [20]. The brains were trimmed to isolate coronal blocks of $7 \mathrm{~mm}$ thickness that contained the injection site in the centre and cut into $10 \mu \mathrm{m}$ thick coronal sections on a cryostat. Sections were collected on APES coated slides for histological examination, quantification studies and immunocytochemistry.

Sections of brain were stained by immunohistochemistry to identify elements characteristic of immune complexes and to study their position in relation to cerebral vascular basement membranes. Complement was identified by antibodies against mouse C3, (FITC conjugated rabbit anti-C3, MP Biomedicals, France), at a dilution of 1:2000. Mouse IgG was identified using FITC labelled F $\left(\mathrm{ab}^{\prime}\right)_{2}$ fragments of goat anti-mouse IgG (Sigma-Aldrich, Dorset, UK), at 1:500 dilution. Rabbit anti-OVA (SigmaAldrich, Dorset, UK) was used at a dilution of 1:1000. Activated macrophages were studied using an F4/80 monoclonal antibody, (AbDserotec, Oxford, UK) at 1:500 dilution.

To assess the distribution of the immune complexes in relation to the cerebrovascular basement membranes, simultaneous staining of the laminin component of vascular basement membranes was performed by immunocytochemistry using a pan-laminin polyclonal rabbit 
antibody (Sigma-Aldrich, Dorset, UK) at a 1:500 dilution. Smooth muscle cells of the tunica media of arteries were identified by detecting $\alpha$-smooth muscle actin using a mouse monoclonal antibody (Sigma-Aldrich, Dorset, UK) at 1:4000 dilution.

\section{Injections of fluorescent tracer}

At 5 minutes, $24 \mathrm{hr}$ and 7 days following the intracerebral injections of OVA, fluorescein labeled $3 \mathrm{kDa}$ soluble lysine fixable dextran (Invitrogen, Paisley, UK) was injected into the striatum, as described previously [2] (Figure 1). Dextran was injected at $1 \mu \mathrm{g} / \mu \mathrm{l}$ in a volume of $0.5 \mu \mathrm{l}$, over a period of 2 minutes through a glass micropipette with the injecting tip $<50 \mu \mathrm{m}$ (Sigma-Aldrich, Dorset, UK) as previously described [2]. Mice were sacrificed at 5 minutes following injection of the tracer.

Tissue was collected after terminal anaesthesia with sodium pentobarbitone (250-300 $\mu \mathrm{l}$ intraperitoneally) and transcardially perfusion with heparinized $0.9 \%$ saline followed by $4 \%$ paraformaldehyde in $0.1 \mathrm{M}$ phosphate buffer $\mathrm{pH}$ 7.4. Brains were removed and further fixed by immersion in 4\% paraformaldehyde for 4-6 hours and placed in $30 \%$ sucrose for $48 \mathrm{~h}$ for cryoprotection. The brains were trimmed to form coronal blocks $7 \mathrm{~mm}$ thick with the injection site in the centre. Blocks were then frozen in Tissue Tek OCT (Sakura Finetek Europe B. V., Zoeterwoude, The Netherlands) and sectioned in a coronal plane $(10 \mu \mathrm{m}$ thick) on a cryostat. Sections were collected on gelatin-coated slides for histological examination, quantification studies and immunocytochemistry.

Secondary antibodies or streptavidin (in the cases where avidin-biotin complex was used) labeled with Alexa Fluor 488 or Alexa Fluor 546 fluorochrome (Invitrogen, Paisley, UK) to enable visualization with a fluorescence microscope. The specificity of the labeling was controlled by omission of the primary antibody. Mounted sections were cover slipped using Vectashield (Vector Labs, Peterborough, UK).

\section{Quantitation of interstitial fluid drainage}

Images of $1030 \times 1030$ pixels per inch were obtained at $\times 25$ magnification at an SP2 Leica Confocal System using sequential scanning. Co-localization of fluorescent markers appeared yellow. The illumination of the specimen provided by the SP2 confocal laser scanning microscope used in this study was restricted to a single point $(\sim 0.25 \mu \mathrm{m}$ in diameter by $\sim 0.5 \mu \mathrm{m}$ deep), scanned across the specimen. By inserting a confocal imaging aperture into the light path, the resulting image comprises mainly in-focus information from the focal plane whilst the majority of the out-of-focus flare (associated with conventional microscopy) was eliminated. Thus, a series of in-focus $1 \mu \mathrm{m}$ optical sections were acquired and combined to produce a sharp 3 dimensional image of the whole specimen.

\section{Co-localization technique}

When two spectra for different labels (i.e. double labeling) are acquired, two data sets are produced (one for each fluorochrome). The SP2 Leica software compares the labeling intensity from the two data sets, voxel by voxel; if there is no labeling in either corresponding voxel it appears black, labeling in one but not the other voxel appears green (or red). Whenever a high intensity of labeling in both channels is detected, the programme converts the point to a chosen colour (for images in this thesis, blue or yellow). To minimize false positives due to fluorescence detected in both channels ("bleed through"), sequential rather than simultaneous acquisition of data sets for each fluorochrome was performed.

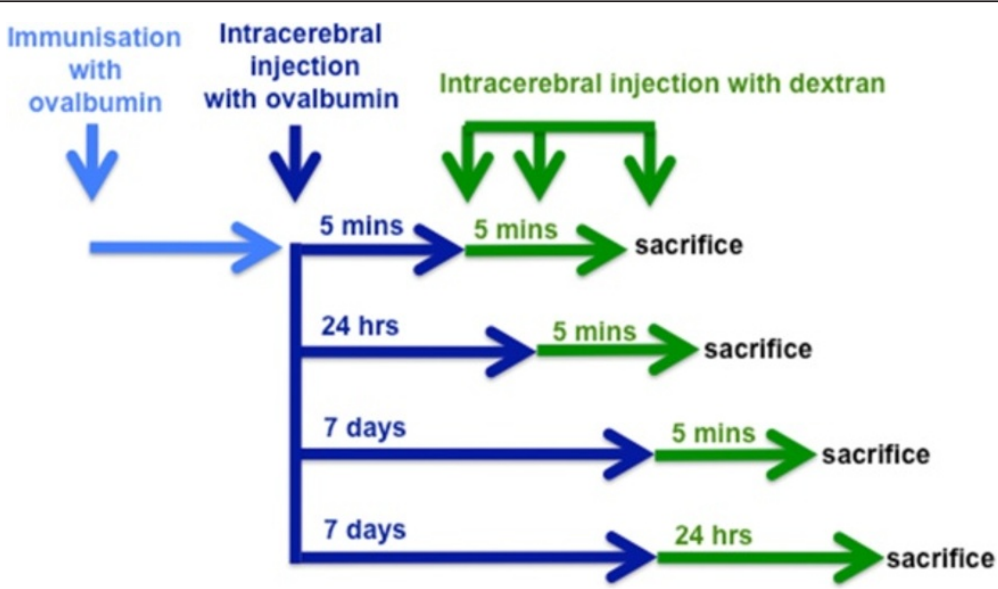

Figure 1 Schematic demonstrating the temporal sequence of immunization and injection experiments. Wild type BALB/C mice were immunized with OVA and then injected with OVA in the striatum at different time points. A soluble fixable fluorescent dextran was then injected intracerebrally at 5 mins or $24 \mathrm{~h}$ or 7 days post-immunization. Mice were examined at 5 minutes after injections of dextran. 
The number of blood vessels with dextran in their walls or in perivascular cells was quantified within the confocal images, using the KS-400 software on a Zeiss Image Analysis. Five images were taken for each section. The area within which the blood vessels were counted in each image was of $391193 \mu \mathrm{m}^{2}$. The number of blood vessels outlined with dextran was used for graphical and statistical analysis. All statistical tests were carried out using SPSS 16.0. Two way ANOVA test with Bonferroni correction was applied and values of $\mathrm{p}<0.05$ were considered statistically significant. The type of blood vessels was determined by their diameter and the presence of smooth muscle actin. Vessels were considered to be capillaries if their diameter was under $10 \mu \mathrm{m}$ and if they lacked smooth muscle actin staining; arteries were defined by a diameter greater than $10 \mu \mathrm{m}$ and by the presence of smooth muscle actin staining in their walls. Veins were larger than $10 \mu \mathrm{m}$ in diameter and lacked smooth muscle actin.
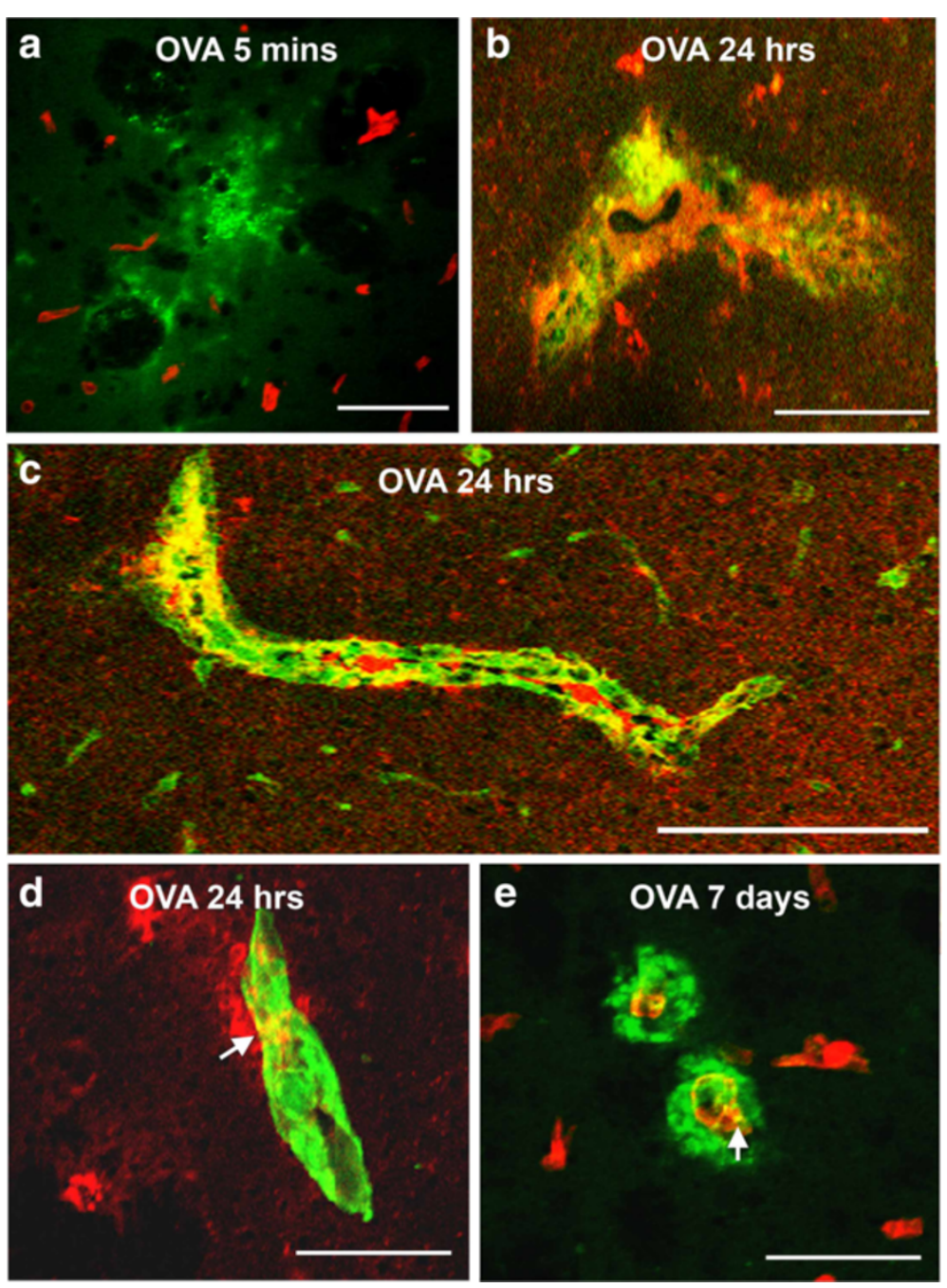

Figure 2 Immune complexes in basement membranes in the walls of cerebral capillaries and arteries. Active immunization with OVA was followed by intracerebral challenge with OVA and left in situ for (a) 5 mins, (b-d) 24 hours and (e) 7 days. (a) At 5 mins, complement C3 (green) is diffusely in the vicinity of blood vessels stained for laminin (red); there is no co-localization of complement and laminin. (b) At 24 hours, lgG (red) is seen distributed diffusely in the perivascular brain parenchyma and is co-localized (yellow) with complement C3 (green) in brain parenchyma. (c) At 24 hours after injection of antigen, a longitudinal section of an artery in the striatum shows co-localization (yellow) of complement (green) with laminin (red) in the basement membranes surrounding smooth muscle cells in the tunica media. (d) lgG (red) is present in the brain parenchyma and co-localizes (yellow) with laminin (green) in a blood vessel wall at 24 hours. (e) At 7 days, complement C3 (green) is distributed circumferentially around blood vessels (red=laminin). Some co-localization of complement C3 and laminin (yellow) is still seen in the blood vessel walls. Confocal images: co-localization appears as a yellow colour. Scale bars $=60 \mu \mathrm{m}$. 


\section{Results}

Relation of immune complexes to the cerebral vasculature following intracerebral injection of ovalbumin in ovalbumin- immunized mice

The immunization protocol has been shown in previous studies to generate high levels of circulating OVA specific antibodies, with half maximal binding within dilutions of $1: 10^{5}-1: 10^{7}$, demonstrated in a previous related study [20].

We previously showed that intracerebral injection of OVA in OVA-immunized mice results in immune complex formation and inflammation around cerebral blood vessels [20]. In the current study we aimed to investigate the kinetics and location of the immune complexes in more detail and to test the hypothesis that the perivascular drainage of solutes is affected under these conditions. To analyze immune complex formation following intracerebral OVA injection at different time points, we first stained tissue from non-immunized and OVA immunized mice for OVA, IgG, and C3. Laminin was used to identify the location of the immune complex within the blood vessel wall (Figure 2). Five minutes and three hours after its injection in immunized mice, OVA was diffusely spread in the ipsilateral striatum, corpus callosum and cortex as described previously [2]. Around the injection site for OVA, Complement C3 and IgG were present on both sides of the laminin of capillaries of OVA immunized mice (Figure 2a). IgG was seen within the lumen of blood vessels, with little extravasation in the perivascular space. The staining for $\mathrm{C} 3$ was diffuse and limited only to the injection site, without any C3 observed in basement membranes. Non-immunized control mice showed minimal levels of IgG and C3 (data not shown).

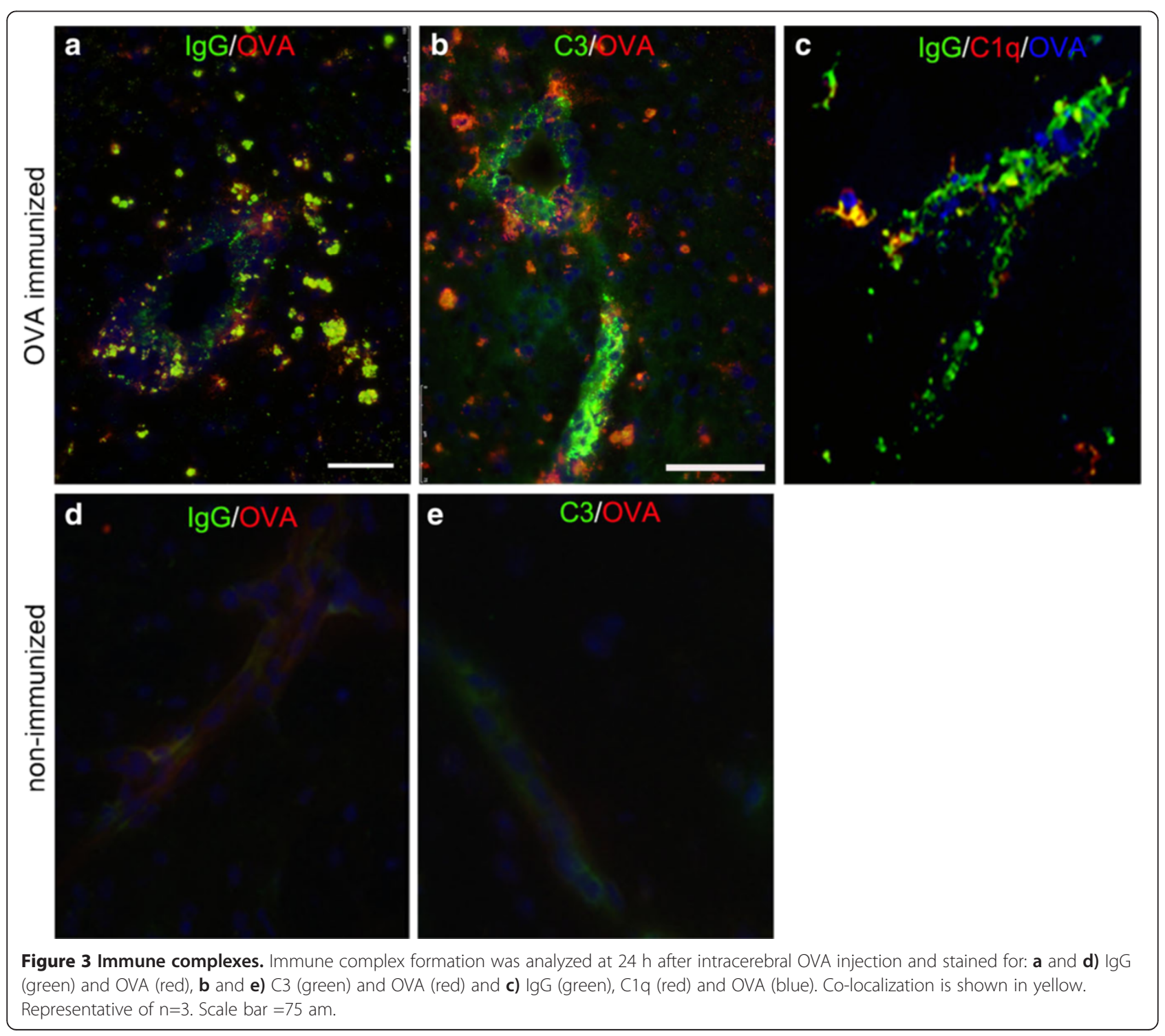


At twenty-four hours, IgG, C3 and OVA were identified in the brain in close proximity to the cerebral vasculature and double staining for IgG and laminin revealed that IgG and complement C3 were present in the parenchyma and also co-localized with laminin present in the walls of blood vessels (Figure 2b-d). Staining for IgG, OVA, C3 and C1q confirmed the presence of immune complexes in the parenchyma and their association with blood vessels (Figure 3). OVA was no longer detectable in association with the cerebrovascular basement membranes at 7 days (Figure 2e).

\section{Reduced perivascular drainage of dextran tracer in the presence of immune complexes}

Having demonstrated that immune complexes are formed in the basement membrane, $24 \mathrm{~h}$, but not yet at 5 minutes, after intracerebral injection of OVA, we next investigated perivascular drainage in the presence of immune complexes by co- injecting a fluorescent tracer at 5 minutes, $24 \mathrm{~h}$ and 7 days following the intracerebral injection of OVA.

We previously showed that within five minutes of its injection, fluorescent dextran spreads diffusely and is found at the basement membranes of cerebral capillaries of the grey matter [2]. Therefore we used this time point to test if drainage of dextran is impeded following immune complex formation in the basement membranes of cerebral blood vessels. In a separate group of mice, we allowed dextran to drain for $24 \mathrm{~h}$.

Five minutes after OVA injection, we observed a diffuse distribution of the fluorescent tracer dextran in the extracellular space and within the walls of capillaries and arteries of OVA immunized mice (Figure 4a). This pattern was similar to non-immunized, control animals (data not shown). Quantification of the type of vessels that contained dextran associated with their walls revealed that at 5 minutes after injection of OVA, there was no difference in the number of dextran positive arteries or capillaries, compared to non-immunized controls (Figure $5 \mathrm{a}$ and b). Furthermore, there were no differences in the number of veins labeled with dextran between this group and control animals (Figure 5c).

At $24 \mathrm{~h}$ after OVA injection, dextran had a reticular cuff appearance around laminin in the walls of capillaries and arteries (Figure 4b). Quantification of the number of blood vessels that contained dextran associated with the basement membranes revealed no difference in the number of capillaries with dextran in their walls, compared to non-immunized control mice (Figure 5a). A
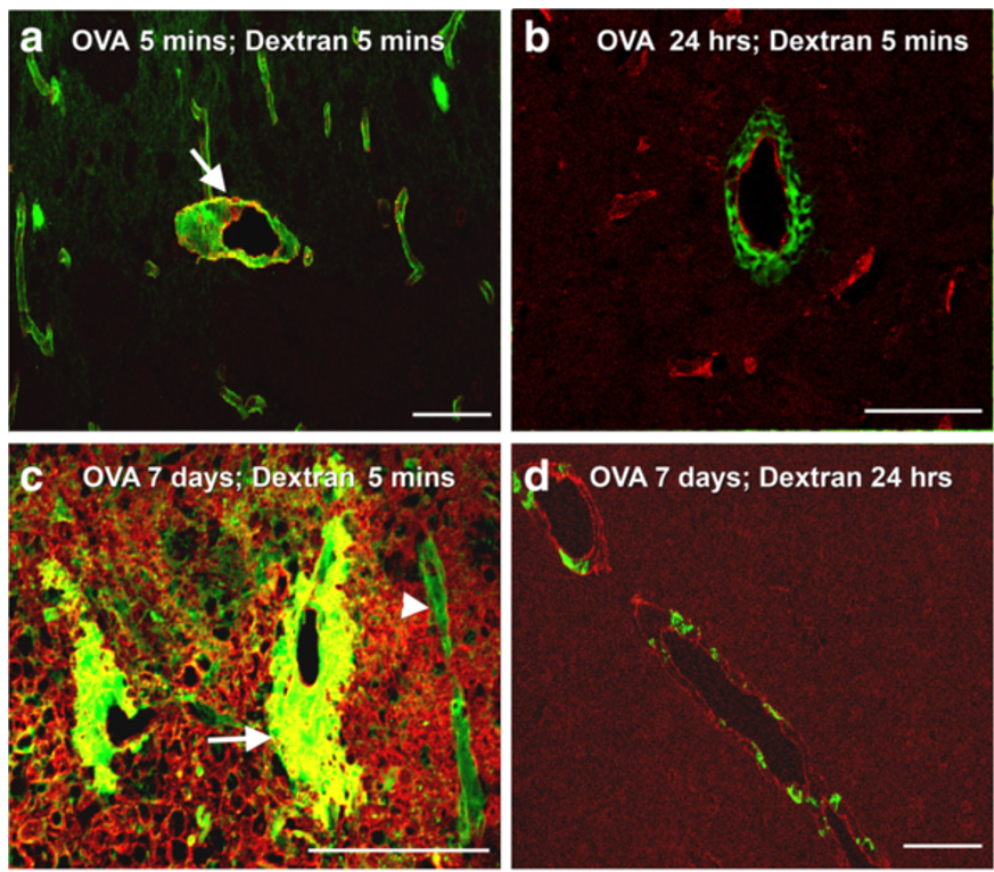

Figure 4 Perivascular drainage of dextran. (a) Following active immunization with OVA, at 5 minutes after the intracerebral injection of OVA and 5 minutes after the injection of dextran (green), the distribution of dextran is diffuse in the extracellular spaces and within the walls of capillaries and arteries. The arrow points to an artery with smooth muscle staining (red). (b) Following active immunization with OVA, at 24 hours after the intracerebral injection of OVA, the dextran injected intracerebrally (green) is present within 5 minutes of its injection as cuffs around vascular laminin (red). (c) In mice actively immunized with OVA, at 7 days after the intracerebral injection of OVA, dextran (green) is in the walls of blood vessels (arrowhead) and present within cuffs around large blood vessels (arrow). (d) In mice actively immunized with OVA, at 7 days after the intracerebral injection of OVA and $24 \mathrm{~h}$ after the intracerebral injection of dextran (green), the dextran is present in cells within a perivascular location (red-laminin). Confocal images: co-localization appears as a yellow colour. Scale bars: a, b, $d=100 \mu \mathrm{m} ; \mathrm{c}=120 \mu \mathrm{m}$. 


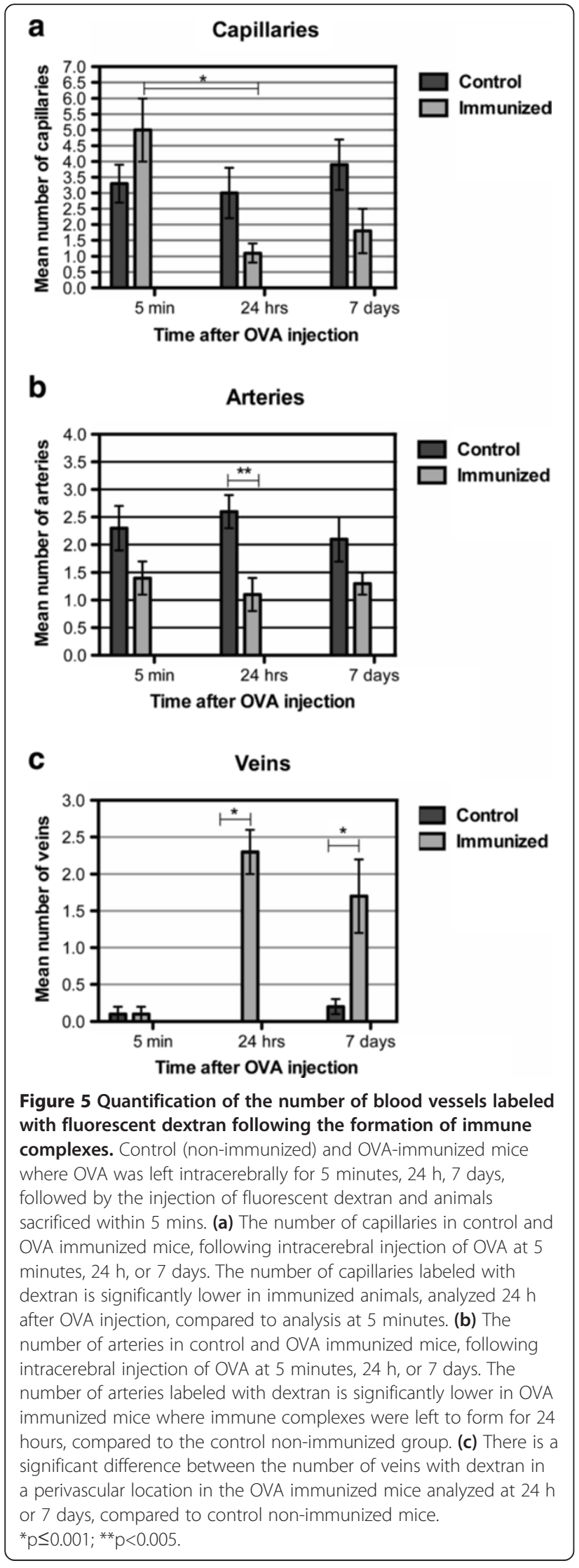

statistically significant reduction in the number of arteries with dextran in their walls was observed compared to controls ( $p=0.003$, Figure $5 b$ ). We further showed that dextran positive veins are significantly higher $(p<0.001$, Figure 5c) in OVA-immunized mice when analyzed $24 \mathrm{~h}$ after intracerebral OVA injection.

At 7 days after immune complex formation the pattern of distribution of dextran was remarkably different between the OVA-immunized and non-immunized groups of mice. In OVA-immunized mice, the diffuse dextran in the extracellular space was confined only to the injection site. The injected dextran outlined the basement membranes of some blood vessels but was also associated with thick perivascular cellular cuffs around other blood vessels (Figure 4c). Staining with smooth muscle actin and subsequent measurement of the diameter of the blood vessels revealed that dextran was present in the walls of capillaries and arteries but the perivascular cuffs with uptake of dextran was present solely around veins and not around arteries or capillaries. In addition, we detected an increased number of F4/80 positive cells in the injection site (Figure 6b). A statistically significant number of veins contained dextran in the surrounding F4/80 positive cells, compared to non-immunized control animals $(\mathrm{p}=0.001$, Figure $5 \mathrm{c})$, while quantification of the number of capillaries and arteries that contained dextran in association with basement membranes revealed no difference (Figure $5 a$ and $5 b$ ).

\section{Discussion}

When OVA is injected into the mouse brain, it diffuses through the extracellular spaces of the grey matter and drains out of the brain along basement membranes in the walls of cerebral capillaries and arteries following the lymphatic drainage pathways of the brain parenchyma [2]. Following immunization of mice using OVA as the antigen, injection of OVA into the brain results in the formation of immune complexes in the parenchyma and this stimulates macrophage invasion and/or microglial activation [20]. The aim of the present paper was to test the hypotheses that a) following the injection of OVA into OVA-immunized mice, immune complexes form within the basement membranes in the walls of cerebral capillaries and arteries and that b) such intramural immune complexes disrupt perivascular lymphatic drainage of solutes from the brain. We present evidence that both these hypotheses have been substantiated.

\section{Location of immune complexes in the walls of cerebral arteries}

The presence of the complement components $\mathrm{C} 1 \mathrm{q}$ and C3, IgG, and OVA was used in the present study as a marker for immune complex formation [22]. Such 

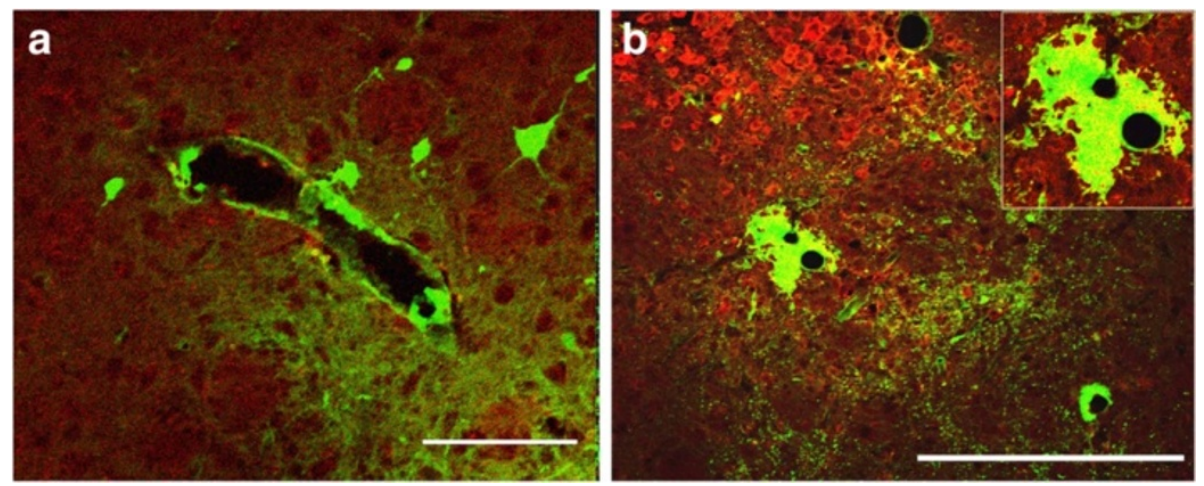

Figure 6 Active immunization with OVA followed by intracerebral challenge with OVA that was then left in situ for $\mathbf{7}$ days. Immune complex formation induces expression of F4/80 on perivascular macrophages and microglia and changes the pattern for the diffusion and elimination of dextran. (a) In non-immunized control mice, dextran (green) outlines the contour of a large blood vessel. Immunofluorescence for F4/80 reveals no staining. (b) 7 days following immune complex formation, F4/80 staining (red) is seen in the parenchyma and adjacent to blood vessels. Dextran (green) forms a large cuff around a blood vessel and is closely associated with the staining for F4/80. The yellow staining within the dextran cuff (inset) indicates co-localization with F4/80. Scale bars $=100 \mu \mathrm{m}$.

immune complexes were detected in the walls of cerebral arteries, co-localizing with laminin in the intramural basement membranes, 24 hours after the injection of OVA into the grey matter of mice immunized against OVA. Co-localization of the components of immune complexes with laminin was identified by confocal microscopy using immunocytochemistry.

\section{Immune complexes in the walls of cerebral arteries} disrupt perivascular drainage of solutes from the brain Normally, when solutes of different molecular weights like OVA, monomeric soluble $\mathrm{A} \beta$ or $3 \mathrm{kDa}$ dextran are injected into the grey matter of the mouse brain, they diffuse rapidly through the interstitial spaces and can be located in the basement membranes in the walls of cerebral capillaries and arteries within 5 min of injection. In this study, we tested the hypothesis that immune complexes within basement membranes would disrupt the perivascular drainage of solutes. Our results showed disruption of perivascular drainage of dextran 24 hours after the injection of OVA into OVA-immunized mice and at the same time that immune complexes were located in vascular basement membranes. The coincidence of immune complexes in arterial basement membranes and disruption of perivascular drainage of dextran is further emphasized by the finding that immune complexes were no longer present in the basement membranes of arteries 7 days after the injection of OVA in immunized mice.

\section{Effects of inflammation on perivascular drainage}

Seven days following the intracerebral injection OVA into OVA-immunized mice, there was extensive perivenous accumulation of inflammatory cells in the brain. The inflammatory reaction resulted in distortion of distribution of the dextran tracer injected into the brain. Dextran accumulated in the enlarged perivenous spaces and was presumably taken up by activated macrophages. Although there was a trend for a reduced number of capillaries and arteries showing dextran in the walls in the 7 day OVAimmunized animals, it did not reach statistical significance. This suggests that the presence of perivenous inflammatory cuffs at this time-point does not have a significant effect on perivascular drainage of solutes along the walls of capillaries and cerebral arteries.

Perivascular macrophages normally take up tracers such as dextran and $A \beta$ that are injected into the brain parenchyma $[2,23]$. By 24 hours after the injection of dextran into normal mice, dextran is only present in perivascular macrophages around arteries in the ipsilateral hemisphere and no dextran is detected within basement membranes in artery walls. In immunized mice that had formed immune complexes and were examined 24 hours after the injection of dextran, perivascular macrophages had taken up dextran around arteries in the parenchyma in the vicinity of the injection and around veins. This suggests that perivascular macrophages play a key role in clearing solutes from the brain when perivascular drainage is disrupted.

\section{Implications for $A \beta$ immunotherapy in Alzheimer's disease}

Following $\mathrm{A} \beta$ immunization in $\mathrm{AD}$, there is an increase in $A \beta 42$ in capillary and artery walls $[18,24,25]$. $A \beta 40$ is usually the predominant amyloid in vessel walls and $A \beta 42$ is detected mainly in parenchymal plaques. Increased amounts of $A \beta 42$ in vessel walls following immunization appear to be the result of solubilization of the parenchymal plaques $[18,24]$ allowing more $A \beta 42$ to reach the drainage channels in capillary and artery walls, accompanied by vasogenic oedema [19]. 
There are no reports of immune complexes formed in the brains of immunized humans against $A \beta$. However, it is possible that $A \beta$ solubilized from plaques may encounter $A \beta$ - specific antibodies generated in the process of immunotherapy in the walls of cerebral blood vessels. High levels of complement have been reported in transgenic mice that harbour $\mathrm{A} \beta$ mutations and that complement co-localizes with the microvascular A $\beta$ [26]. Increased levels of C3 were also found to associate with increased haemorrhages following experimental immunotherapy [27-30], and de-glycosylated antibodies, with reduced complement binding activity, show reduced haemorrhages in an experimental mouse model, suggesting an important role of the effector function of therapeutic antibodies in the development of these side effects [31]. It has been reported that, following immunotherapy with $A \beta$ in mouse models, small amounts of anti-A $\beta$ antibodies enter the brain and form immune complexes that are cleared from the brain into the blood via the neonatal Fc receptors present ubiquitously in the endothelia [32]. In our model, in wild type mice, we observed accumulation of OVA in perivascular macrophages, arguing against the removal of immune complexes via this receptor. A possible explanation may be due to the high antibody titers in our model, leading to higher levels of immune complexes (excess IgG) that saturate efflux mechanisms via FcRn.
The risk of intracerebral haemorrhage may increase if immune complexes are formed in the basement membranes of capillaries and arteries affected by CAA, as the wall is already structurally weak from the deposition of $A \beta$ and is predisposed to aneurysm and rupture $[9,21,33]$. Recently it has been shown that active immunotherapy using $\mathrm{A} \beta$ derivatives and alum in adult but not old Tg2576 mice results in a reduction of $A \beta$ burden, without worsening of CAA or inducing microhaemmorhages [34]. In the light of the findings of our study, if blood vessels are still unaffected by the morphological changes associated with senescence and deposition of $A \beta$, they may accommodate the drainage of the $A \beta$ solubilized from plaques, without rupturing the vascular wall. This is particularly important in the light of new immunization protocols that are administered early, before AD pathology is advanced [35,36].

\section{Conclusions}

Our results demonstrate that immune complexes that are present within the walls of arteries interfere with perivascular drainage of solutes. Inflammation associated with the presence of immune complexes results in a sequestering of solutes within inflammatory cells. We do not know whether immune complexes form in the extracellular spaces of the brain and then drain via perivascular routes, or whether they form within the arterial basement membranes (Figure 7). It remains to be

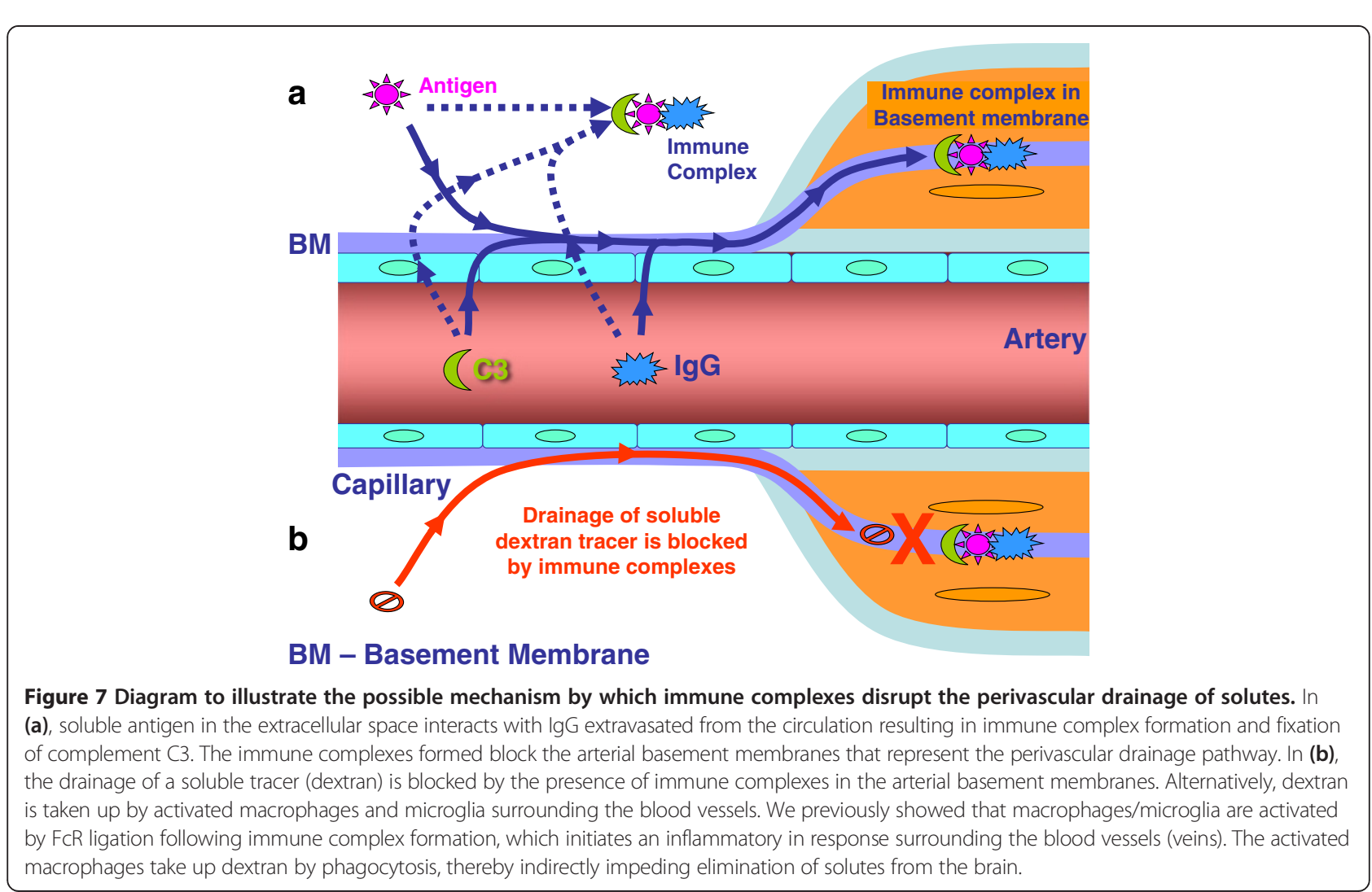


clarified to what extent immune complexes are formed after immunization with $A \beta$ and the proportion of capillaries and arteries that remain functional to allow the drainage of solubilized $A \beta$ and other metabolites. Future prophylactic and therapeutic strategies in ageing and CAA will aim to test chaperone molecules that may facilitate drainage along cerebrovascular basement membranes even if immune complexes reside in them.

\section{Competing interest}

The authors declare that they have no conflict of interest.

\section{Authors' contributions}

$\mathrm{RC}, \mathrm{VP}, \mathrm{ROW}, \mathrm{JN}$ and JT designed the study. RC carried out the intracerebral injections of OVA and dextran, prepared the tissue, analyzed the pattern of perivascular drainage drafted the manuscript. JT and UP immunized the mice and analyzed the immune complexes. $\mathrm{CH}$ performed the quantification and statistical analysis. All authors contributed to the manuscript, read and approved the final manuscript.

\section{Acknowledgements}

This work was supported by Alzheimer's Research UK.

\section{Author details}

${ }^{1}$ Faculty of Medicine, University of Southampton, Southampton, UK. ${ }^{2}$ Centre for Biological Sciences, University of Southampton, Southampton, UK. ${ }^{3}$ Clinical Neurosciences, South Lab and Pathology Block, LD66 (Mailpoint 806), Southampton General Hospital, Tremona Road, Southampton, Hampshire SO16 6YD, United Kingdom.

Received: 5 August 2013 Accepted: 5 August 2013

Published: 9 August 2013

\section{References}

1. Cserr HF, Cooper DN, Suri PK, Patlak CS: Efflux of radiolabeled polyethylene glycols and albumin from rat brain. AmJ Physiol 1981, 240(4):F319-F28.

2. Carare RO, Bernardes-Silva M, Newman TA, Page AM, Nicoll JA, Perry VH, et al: Solutes, but not cells, drain from the brain parenchyma along basement membranes of capillaries and arteries: significance for cerebral amyloid angiopathy and neuroimmunology. Neuropatho/App/Neurobiol 2008, 34(2):131-44.

3. Weller RO, Boche D, Nicoll JA: Microvasculature changes and cerebral amyloid angiopathy in Alzheimer's disease and their potential impact on therapy. Acta neuropathologica 2009, 118(1):87-102.

4. Attems J: Sporadic cerebral amyloid angiopathy: pathology, clinical implications, and possible pathomechanisms. Acta Neuropathol(Berl) 2005, 110(4):345-59.

5. Attems J, Jellinger K, Thal DR, Van Nostrand W: Review: sporadic cerebral amyloid angiopathy. Neuropathology and applied neurobiology 2011, 37(1):75-93. Epub 2010/10/16.

6. Kawai M, Kalaria RN, Cras P, Siedlak SL, Velasco ME, Shelton ER, et al: Degeneration of vascular muscle cells in cerebral amyloid angiopathy of Alzheimer disease. Brain research. 1993, 623:142-6.

7. Frackowiak J, Zoltowska A, Wisniewski HM: Non-fibrillar beta-amyloid protein is associated with smooth muscle cells of vessel walls in Alzheimer disease. J Neuropathol Exp Neurol 1994, 53(6):637-45.

8. Preston SD, Steart PV, Wilkinson A, Nicoll JA, Weller RO: Capillary and arterial cerebral amyloid angiopathy in Alzheimer's disease: defining the perivascular route for the elimination of amyloid beta from the human brain. NeuropatholApp/ Neurobiol 2003, 29(2):106-17.

9. McCarron MO, Nicoll JA: Cerebral amyloid angiopathy and thrombolysisrelated intracerebral haemorrhage 6. Lancet Neurol 2004, 3(8):484-92.

10. Werring DJ, Sperling R: Inflammatory cerebral amyloid angiopathyand amyloid-modifying therapies: Variations on the same ARIA? Annals of neurology 2013. Epub 2013/03/26.

11. Lue LF, Kuo YM, Roher AE, Brachova L, Shen Y, Sue L, et al: Soluble amyloid beta peptide concentration as a predictor of synaptic change in Alzheimer's disease. AmJ Pathol 1999, 155(3):853-62
12. Mawuenyega KG, Sigurdson W, Ovod V, Munsell L, Kasten T, Morris JC, et al: Decreased clearance of CNS beta-amyloid in Alzheimer's disease. Science 2010, 330(6012):1774. Epub 2010/12/15

13. Schenk D, Barbour R, Dunn W, Gordon G, Grajeda H, Guido T, et al: Immunization with amyloid-beta attenuates Alzheimer-disease-like pathology in the PDAPP mouse. Nature 1999, 400(6740):173-7.

14. Cribbs DH, Agadjanyan MG: Active and passive Abeta-immunotherapy: preclinical and clinical studies and future directions: part II. CNS \& neurological disorders drug targets 2009, 8(2):82-7.

15. Nicoll JA, Wilkinson D, Holmes C, Steart P, Markham H, Weller RO: Neuropathology of human Alzheimer disease after immunization with amyloid-beta peptide: a case report. NatMed 2003, 9(4):448-52.

16. Ferrer I, Boada RM, Sanchez Guerra ML, Rey MJ, Costa-Jussa F: Neuropathology and pathogenesis of encephalitis following amyloidbeta immunization in Alzheimer's disease 49. Brain Pathol 2004, 14(1):11-20

17. Masliah E, Hansen L, Adame A, Crews L, Bard F, Lee C, et al: Abeta vaccination effects on plaque pathology in the absence of encephalitis in Alzheimer disease. Neurology 2005, 64(1):129-31.

18. Boche D, Zotova E, Weller RO, Love S, Neal JW, Pickering RM, et al: Consequence of Abeta immunization on the vasculature of human Alzheimer's disease brain. Brain: a journal of neurology 2008, 131(Pt 12):3299-310.

19. Sperling R, Salloway S, Brooks DJ, Tampieri D, Barakos J, Fox NC, et al: Amyloid-related imaging abnormalities in patients with Alzheimer's disease treated with bapineuzumab: a retrospective analysis. Lancet neurology 2012, 11(3):241-9. Epub 2012/02/07.

20. Teeling $\mathrm{JL}$, Carare RO, Glennie MJ, Perry VH: Intracerebral immune complex formation induces inflammation in the brain that depends on $\mathrm{Fc}$ receptor interaction. Acta neuropathologica 2012, 124(4):479-90.

21. McCarron MO, Nicoll JA: Recurrent hemorrhage in cerebral amyloid angiopathy 68. Neurology 1998, 51(3):924-5.

22. Sjoberg AP, Trouw LA, Blom AM: Complement activation and inhibition: a delicate balance. Trends Immunol 2009, 30(2):83-90.

23. Kida S, Steart PV, Zhang ET, Weller RO: Perivascular cells act as scavengers in the cerebral perivascular spaces and remain distinct from pericytes, microglia and macrophages. Acta Neuropathol(Berl) 1993, 85(6):646-52.

24. Nicoll JA, Barton E, Boche D, Neal JW, Ferrer I, Thompson P, et al: Abeta species removal after abeta42 immunization. JNeuropatholExpNeurol 2006, 65(11):1040-8.

25. Wilcock DM, Jantzen PT, Li Q, Morgan D, Gordon MN: Amyloid-beta vaccination, but not nitro-nonsteroidal anti-inflammatory drug treatment, increases vascular amyloid and microhemorrhage while both reduce parenchymal amyloid. Neuroscience 2007, 144(3):950-60.

26. Fan R, Defilippis K, Van Nostrand WE: Induction of complement proteins in a mouse model of cerebral microvascular Abeta deposition. JNeuroinflammation 2007, 4(1):22.

27. Petrushina I, Ghochikyan A, Mktrichyan M, Mamikonyan G, Movsesyan N, Davtyan $\mathrm{H}$, et al: Alzheimer's disease peptide epitope vaccine reduces insoluble but not soluble/oligomeric Abeta species in amyloid precursor protein transgenic mice. The Journal of neuroscience: the official journal of the Society for Neuroscience 2007, 27(46):12721-31.

28. Vasilevko V, Xu F, Previti ML, Van Nostrand WE, Cribbs DH: Experimental investigation of antibody-mediated clearance mechanisms of amyloidbeta in CNS of Tg-SwDI transgenic mice. J Neurosci 2007, 27(49):13376-83.

29. Head E, Barrett EG, Murphy MP, Das P, Nistor M, Sarsoza F, et al: Immunization with fibrillar Abeta(1-42) in young and aged canines: Antibody generation and characteristics, and effects on CSF and brain Abeta. Vaccine 2006, 24(15):2824-34.

30. Cribbs DH, Ghochikyan A, Vasilevko V, Tran M, Petrushina I, Sadzikava N, et al: Adjuvant-dependent modulation of Th1 and Th2 responses to immunization with beta-amyloid. Int Immunol 2003, 15(4):505-14.

31. Wilcock DM, Munireddy SK, Rosenthal A, Ugen KE, Gordon MN, Morgan D: Microglial activation facilitates Abeta plaque removal following intracranial anti-Abeta antibody administration. Neurobiol Dis 2004, 15(1):11-20.

32. Deane R, Bell RD, Sagare A, Zlokovic BV: Clearance of amyloid-beta peptide across the blood-brain barrier: implication for therapies in Alzheimer's disease. CNS \& neurological disorders drug targets 2009, $8(1): 16-30$

33. Carlson C, Estergard W, Oh J, Suhy J, Jack CR Jr, Siemers E, et al: Prevalence of asymptomatic vasogenic edema in pretreatment Alzheimer's disease 
study cohorts from phase 3 trials of semagacestat and solanezumab. Alzheimer's \& dementia: the journal of the Alzheimer's Association 2011, 7(4):396-401. Epub 2011/07/26.

34. Asuni AA, Boutajangout A, Scholtzova H, Knudsen E, Li YS, Quartermain D, et al: Vaccination of Alzheimer's model mice with Abeta derivative in alum adjuvant reduces Abeta burden without microhemorrhages. EurJNeurosci 2006, 24(9):2530-42.

35. Davtyan H, Ghochikyan A, Petrushina I, Hovakimyan A, Davtyan A, Poghosyan A, et al: Immunogenicity, efficacy, safety, and mechanism of action of epitope vaccine (Lu AF20513) for Alzheimer's disease: prelude to a clinical trial. The Journal of neuroscience: the official journal of the Society for Neuroscience 2013, 33(11):4923-34. Epub 2013/03/15.

36. Winblad B, Andreasen N, Minthon L, Floesser A, Imbert G, Dumortier T, et al: Safety, tolerability, and antibody response of active Abeta immunotherapy with CAD106 in patients with Alzheimer's disease: randomised, double-blind, placebo-controlled, first-in-human study. Lancet neurology 2012, 11(7):597-604. Epub 2012/06/09.

doi:10.1186/2051-5960-1-48

Cite this article as: Carare et al: Immune complex formation impairs the elimination of solutes from the brain: implications for immunotherapy in Alzheimer's disease. Acta Neuropathologica Communications 2013 1:48.

\section{Submit your next manuscript to BioMed Central and take full advantage of:}

- Convenient online submission

- Thorough peer review

- No space constraints or color figure charges

- Immediate publication on acceptance

- Inclusion in PubMed, CAS, Scopus and Google Scholar

- Research which is freely available for redistribution 